University of Texas Rio Grande Valley

ScholarWorks @ UTRGV

$9-2021$

\title{
Investigating the Relationship between Effectiveness of App Evolution and App Continuance Intention: An Empirical Study of the U.S. App Market
}

Yi Liu

Xuan Wang

The University of Texas Rio Grande Valley

Jiahe Song

Xinlin Tang

Follow this and additional works at: https://scholarworks.utrgv.edu/is_fac

Part of the Business Commons

\section{Recommended Citation}

Liu, Y., Song, J., Wang, X., \& Tang, X. (2021). Investigating the Relationship between the Effectiveness of App Evolution and App Continuance Intention: An Empirical Study of the U.S. App Market. Communications of the Association for Information Systems, 49, pp-pp. https://doi.org/10.17705/ 1CAIS.04909

This Article is brought to you for free and open access by the Robert C. Vackar College of Business \& Entrepreneurship at ScholarWorks @ UTRGV. It has been accepted for inclusion in Information Systems Faculty Publications and Presentations by an authorized administrator of ScholarWorks @ UTRGV. For more information, please contact justin.white@utrgv.edu,william.flores01@utrgv.edu. 


\section{Communications of the Association for Information Systems}

$9-21-2021$

\section{Investigating the Relationship between the Effectiveness of App Evolution and App Continuance Intention: An Empirical Study of the U.S. App Market}

Yi Liu

University of the Incarnate Word, yiliu5@uiwtx.edu

Jiahe Song

Western Michigan University, carrie.song@wmich.edu

Xuan Wang

The Universioty of Texas Rio Grande Valley, xuan.wang@utrgv.edu

Xinlin Tang

Florida State University, xtang2@business.fsu.edu

Follow this and additional works at: https://aisel.aisnet.org/cais

\section{Recommended Citation}

Liu, Y., Song, J., Wang, X., \& Tang, X. (2021). Investigating the Relationship between the Effectiveness of App Evolution and App Continuance Intention: An Empirical Study of the U.S. App Market. Communications of the Association for Information Systems, 49, pp-pp. https://doi.org/10.17705/ 1CAIS.04909

This material is brought to you by the AIS Journals at AIS Electronic Library (AISeL). It has been accepted for inclusion in Communications of the Association for Information Systems by an authorized administrator of AIS Electronic Library (AISeL). For more information, please contact elibrary@aisnet.org. 


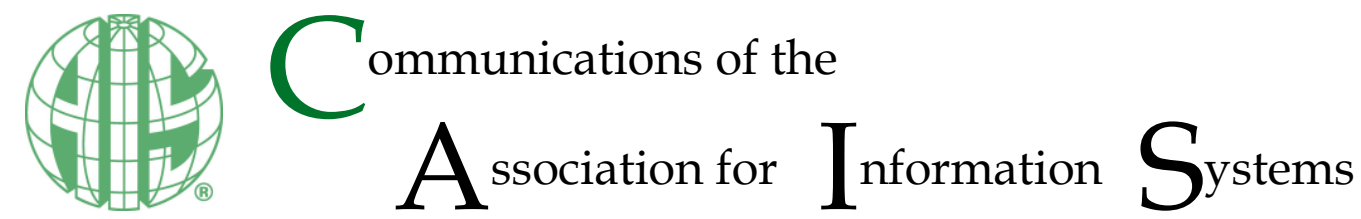

\section{Investigating the Relationship between the Effectiveness of App Evolution and App Continuance Intention: An Empirical Study of the U.S. App Market}

\author{
Yi Liu \\ H-E-B School of Business \& Administration \\ University of the Incarnate Word \\ yiliu5@uiwtx.edu \\ Xuan Wang \\ Robert C. Vackar College of Business and \\ Entrepreneurship \\ University of Texas Rio Grande Valley \\ xuan.wang@utrgv.edu
}

\author{
Jiahe Song' \\ Haworth College of Business \\ Western Michigan University \\ carrie.song@wmich.edu \\ Xinlin Tang \\ College of Business \\ Florida State University \\ xtang2@business.fsu.edu
}

Abstract:

Researchers have shown app evolution to continuously lead to app success from the developer perspective. However, few studies have explored app success from the user perspective, which limits our knowledge about the role that app evolution has in app success. Building on app evolution literature and the technology acceptance model (TAM), we investigate the influence that effectiveness of app evolution has on perceived app usefulness, perceived ease of use, and app continuance intention (a proxy for app success from the user perspective). We collected survey data from 299 app users on both the Google Play and Apple's App Store platforms in the United States. Our findings indicate that effectiveness of strategic evolution and effectiveness of evolution speed directly affect perceived app usefulness, while effectiveness of operational evolution and effectiveness of evolution speed directly affect perceived app ease of use. In addition, perceived app usefulness and perceived app ease of use constitute two key factors that lead to app continuance intention. Perceived ease of use affects users' app continuance intention both directly and indirectly through perceived app usefulness. This study enhances our knowledge about the relationship between effectiveness of app evolution and app continuance intention. Such knowledge has particular importance in helping small firms or startups with limited resources understand how to retain app users. We also discuss limitations and directions for future research.

Keywords: App Evolution, Platform Ecosystems, App Continuous Intention, Google Play, Apple's App Store.

This manuscript underwent peer review. It was received 3/28/2020 and was with the authors for ten months for two revisions. The Associate Editor chose to remain anonymous.

\footnotetext{
${ }^{1}$ Corresponding author.
} 


\section{Introduction}

Mobile devices have become increasingly popular among individuals and organizations in the "mobile economy" era (Morgan, 2017; Sivakumaran \& lacopino, 2018). These mobile devices occupy 65 percent of users' digital media time (Sterling, 2016) and contribute approximately US\$1 trillion in revenue to the digital market (Sivakumaran \& lacopino, 2018). As mobile devices have risen in popularity and significance, platform-centric ecosystems have also emerged to play a major role in today's business. A platform-centric ecosystem comprises a mobile platform and mobile apps. A mobile platform (e.g., Android, iOS) is a software-based platform that provides basic functionalities for mobile devices (Tiwana, Konsynski, \& Bush, 2010). Mobile apps complement a platform's functionalities by adding new features to the platform and, thus, allow app users to perform specific tasks on the platform (Liu, Au, \& Choi, 2014). Recent industrial studies indicate that users downloaded approximately 204 billion apps onto mobile devices in 2019 (Statista, 2020). Moreover, sources expect app revenue to grow from US $\$ 365.2$ billion in 2018 to US $\$ 935.2$ billion in 2023 (Statista, 2019). App markets have become attractive and fast-growing markets. Also, app markets have comparatively low barriers to entry and many similar competing apps (Wang, Li, \& Singh, 2018). These factors make app markets highly dynamic and, thus, app success temporary. Thus, developers need to know how to keep apps profitable in such a competitive market.

Previous studies have examined app success in initial adoption (e.g., app download, app sales) and indicate that an app's visual design (Wang \& Li, 2017) and online feedback (e.g., rank, ratings, reviews) (Carare, 2012; Claussen, Kretschmer, \& Mayrhofer, 2013, Liang, Li, Yang, \& Wang, 2015) play important roles in influencing users' initial app adoption behavior as measured by app downloads and sales. However, app revenue is largely generated by app continuance use (Adjust, 2020; Delisle, 2017). Recent reports indicate that app retention rates have not exceeded more than 30 percent over the past eight years, and more than 70 percent of app users stopped using an app in the first three months (lqbal, 2019). In addition, 25 percent of app users only used an app once (Rodde, 2018). Thus, understanding what drives app continuance intention will help developers retain users and succeed.

Extending the traditional technology acceptance model (TAM) to continuance use, scholars claim that perceived usefulness (PU) and perceived ease of use (PEOU) remain two core factors that help users determine whether to continuously use certain technology (Islam, Mäntymäki, \& Bhattacherjee, 2017; Venkatesh, Thong, Chan, Hu, \& Brown, 2011). Recent studies have adopted this extended model to identify their antecedents and their impacts on initial or continuance intention in the app context (Agrebi \& Jallais, 2015; Cho, 2016; Hsiao, Chang, \& Tang, 2016). Although these studies have generated important insights, they focused only these constructs' determinants at a single time. Apps constitute evolvable systems that can efficiently adapt to serve new purposes and emerging possibilities (Agarwal \& Tiwana, 2015). Therefore, developers-especially small firms or startups that do not have resources for professional, third party marketing services to help them understand their users - need to understand how to continuously influence PU and PEOU, two key influential factors that influence app continuance intention.

Scholars have extended the evolutionary perspective, which comes from biological evolution in natural sciences, into the IS field to explain continuous app success (Tiwana et al., 2010). As continuous change that leads to an app's incremental improvement, app evolution can help an app constantly address changing user preferences (Agarwal \& Tiwana, 2015), which may result in app continuance intention. Studies on app evolution mainly take the app developer perspective and focus on evolution speed, which refers to the frequency with which developers update an app in a certain period or the absolute evolution speed (Agarwal \& Tiwana, 2015; Tiwana, 2015). However, app evolution involves other attributes beyond speed. Given that successful evolution should not only be fast but also effective (Moore, 1993), evolution content (i.e., what and how an app evolves) constitutes another critical app evolution attribute. In addition, end users determine whether app evolution influences their app continuance intention. Because users can differ in their ability to assimilate app evolution, different users form different perceptions about app evolution (Saffarizadeh, Jabr, \& Keil, 2018). Thus, user perceptions on how effectively an app evolves can be a key factor that influences app continuance intention. Therefore, we integrate the app evolution perspective and technology acceptance model to investigate the influence that effectiveness of app evolution has on how users perceive app usefulness and ease of use and their app continuance intention. By doing so, we advance our knowledge about app evolution and provide app developers with actionable insights. Specifically, we seek to address two research questions (RQ): 
RQ1: Do effectiveness of app evolution content and effectiveness of app evolution speed affect users' perceived app usefulness and perceived app ease of use?

RQ2: Do perceived app usefulness and perceived app ease of use influence app continuance intention?

This paper proceeds as follows: in Section 2, we review the literature on the technology acceptance model (TAM) and app evolution. We also develop a conceptual model and present our hypotheses. In Section 3, we present our research design. In Section 4, we present our results from empirically testing the research model and analyze them. In Section 5, we discuss our findings, the study's limitations, and future research directions. Finally, in Section 6, we conclude the paper.

\section{Literature Review and Hypothesis Development}

The technology acceptance model (TAM) explains the relationship that a user's perceived usefulness and perceived ease of use has with technology continuous use, which indicates the extent to which a user perceives a technology as useful and easy to operate determines whether the user decides to continue using the technology (Davis, 1985, 1989). The evolution perspective in the app research stream indicates that app evolution can influence how a user perceives an app, which, in turn, leads to better app performance. Combining the app evolution perspective with TAM, we propose that effectiveness of app evolution can positively affect how users perceive an app's usefulness and ease of use, which, in turn, will enhance their app continuance intention.

\subsection{TAM Model and App Evolution}

\subsubsection{Technology Acceptance Model}

The technology acceptance model (TAM), together with other models developed from it (such as TAM2 and UTAUT), constitute the dominant theories in individual-level IS adoption/use/rejection studies. Originally developed by Davis (1989), TAM explains user intention with regard to using and accepting a technology. It posits that two major constructs influence users when they encounter a new technology: perceived usefulness and perceived ease of use (Abdullah, Ward, \& Ahmed, 2016; Turel, Serenko, \& Giles, 2011). PU refers to "the degree to which a person believes that using a particular system would enhance his or her job performance" and PEOU to "the degree to which a person believes that using a particular system would be free of effort" (Davis, 1989, p. 320). Over the past three decades, researchers have further developed and extended TAM from different perspectives. For example, Venkatesh and Davis (1996) suggested that both computer self-efficacy and objective usability constitute important PEOU determinants. In another study, Venkatesh and Davis (2000) proposed TAM2 and further revealed that social influence processes and cognitive instrumental processes significantly influence user acceptance. Meanwhile, other scholars tried to integrate TAM and the task-technology fit model and suggested that tool and task-related factors can help explain user acceptance (Dishaw \& Strong, 1999). Synthesizing the rich literature on IT adoption and use, Venkatesh, Morris, Davis, and Davis (2003) proposed the unified theory of acceptance and use of technology (UTAUT), which holistically views factors that affect technology adoption and use decisions. Researchers have applied TAM and its extended models to explain technology adoption in various contexts, such as online streaming (Lee \& Lehto, 2013) and virtual reality device adoption (Manis \& Choi, 2019).

Notwithstanding the popularity of TAM and its related models in IT adoption research, some researchers have made calls to further develop this important theory. For example, as Bagozzi has (2007) pointed out, "the absence of a sound theory and method for identifying the determinants of perceived usefulness and perceived ease of use" (p. 245) has restricted IS researchers from uncovering novel theoretical insights from the technology adoption/acceptance/rejection research. Venkatesh, Thong, and Xu (2016) further indicated that user acceptance research has entered a "crossroads" (p. 329) where researchers should build possible theoretical contributions from further research on novel theoretical mechanisms. To answer these calls, we integrate the app evolution literature with the TAM model to examine to the extent to which effectiveness of app evolution affects PU and PEOU, and, in turn, the extent to which PU and PEOU affect whether users continuously use an app. While researchers have extended existing TAM and related models to explain technology continuous use (Chiu \& Wang, 2008; Marinković, Đorđević, \& Kalinić, 2020; Venkatesh et al., 2011), they have developed them largely for traditional technologies/systems that mainly go through the adoption, continuous use, assimilation, and discontinuity or retirement lifecycle. For an 
evolvable system or application such as a mobile app (Agarwal \& Tiwana, 2015), continuous use no longer constitutes a one-time decision but can happen every time the app evolves. The antecedents that existing adoption models identify may not be able to fully explain continuance intention for evolvable apps. Thus, to better understand continuous use in the app market context, we extend the TAM by identifying progressive app factors as antecedents for user perceptions (perceived ease of use, perceived usefulness) on evolvable applications and how these user perceptions affect user continuance intention. While UTAUT more holistically views factors that may influence continuous use, we specifically draw on the original TAM's core components to capture the essence of this influential theory and maintain parsimony at the same time.

\subsubsection{App Evolution and Effectiveness of App Evolution}

The evolutionary perspective in the social sciences comes from biological evolution in the natural sciences (Nelson \& Winter, 1982; Tellis \& Crawford, 1981). Agarwal and Tiwana (2015), Tiwana (2015), and Tiwana et al. (2010) extended the evolutionary perspective into the IS field to explain continuous app success in app markets. This perspective considers apps organisms that adapt to the external environment (users, market, platform, etc.) through continuous upgrades. One can consider each app upgrade an adaptation. As they accumulate, these upgrades form an app's evolutionary process. Only those apps that can consistently meet changing market demands and user preferences can survive or succeed in the competition (Agarwal \& Tiwana, 2015; Tiwana, 2015).

As Tiwana et al. (2010) have said, "complex systems that evolve at a faster rate and with greater diversity are more likely to evolve to achieve better fit with their environment than those that do not possess these traits" (p. 684), which indicates app evolution can be a multi-faceted construct that includes both speed and content. However, previous studies in this research stream have often focused only on evolution speed (Tiwana, 2015). For example, Tiwana (2015) specifically mentioned that he emphasizes "the speed of evolution rather than evolution itself" (p. 267). We argue that app evolution content (e.g., what and how to evolve the app) can be an equally, if not more, important factor than app evolution speed in app success and use.

To identify app evolution content's different dimensions, we conducted a content analysis of the app evolution history of ten randomly selected apps from Apple's App Store. From this analysis, we found two major types of evolution content: 1) the addition of new features and/or functions to enrich the user experience and enlarge the user base or 2) the refinement of current features to smooth app operations. Correspondingly, we define strategic evolution as the extent to which an app adds new features and operational evolution as the extent to which an app refines existing features. In Table 1, we present an app called AtmosphereLogger's partial evolution history to illustrate these two types of evolution content. After releasing its first version, AtmosphereLogger experienced some bugs, which caused the app to operate poorly. The app's development team later fixed these operational issues in a later update (version 0.2 .1 ) and, thus, smoothed out its operation. In a later version (version 0.2.3), the development team added new export features to the app. Thus, the upgrades from version 0.2.1 to version 0.2.3 included both operational and strategic evolution.

Table 1. Example of App Strategic Evolution and Operational Evolution (AtmosphereLogger)

\begin{tabular}{|c|l|c|}
\hline App version & \multicolumn{1}{|c|}{ Evolution content } & Evolution type \\
\hline \multirow{2}{*}{ Version 0.2.3 } & Added exporting feature & Strategic \\
\cline { 2 - 3 } & Fixed some problems & Operational \\
\hline \multirow{2}{*}{ Version 0.2.1 } & Added exporting feature & Strategic \\
\cline { 2 - 3 } & Fixed some problems & Operational \\
\hline Version 0.1.5 & Improve noise reduction & Operational \\
\hline
\end{tabular}

In addition, the extant literature on app evolution has mainly taken the app developer perspective and focused on absolute evolution speed (Tiwana 2015). Such theorizing and operationalization cannot capture how users react to app evolution content and speed. Since app continuance intention constitutes an individual choice and behavior (Chen, Meservy, \& Gillenson, 2012), not absolute evolution speed but rather how users perceive the effectiveness of app evolution shapes their app continuance intention. Saffarizadeh et al. (2018) supports such a user perspective on app evolution in arguing that users differ in their ability to assimilate app evolution, which indicates that users can perceive app evolution in different 
ways. Webiotic (2019) has proposed a similar perspective in noting that too much and too frequent app evolution can burn out users. Therefore, we take the user perspective and propose effectiveness of app evolution as the core construct in this study. We define effectiveness of strategic evolution as user perceptions about the extent to which an app effectively adds new features and effectiveness of operational evolution as user perceptions about the extent to which an app effectively refines existing features. We draw on Tiwana (2015) to define effectiveness of evolution speed as user perceptions about the rates at which an app's developer(s) effectively release upgraded versions of it. We present the research model in Figure 1 and define the major constructs in Table 2.

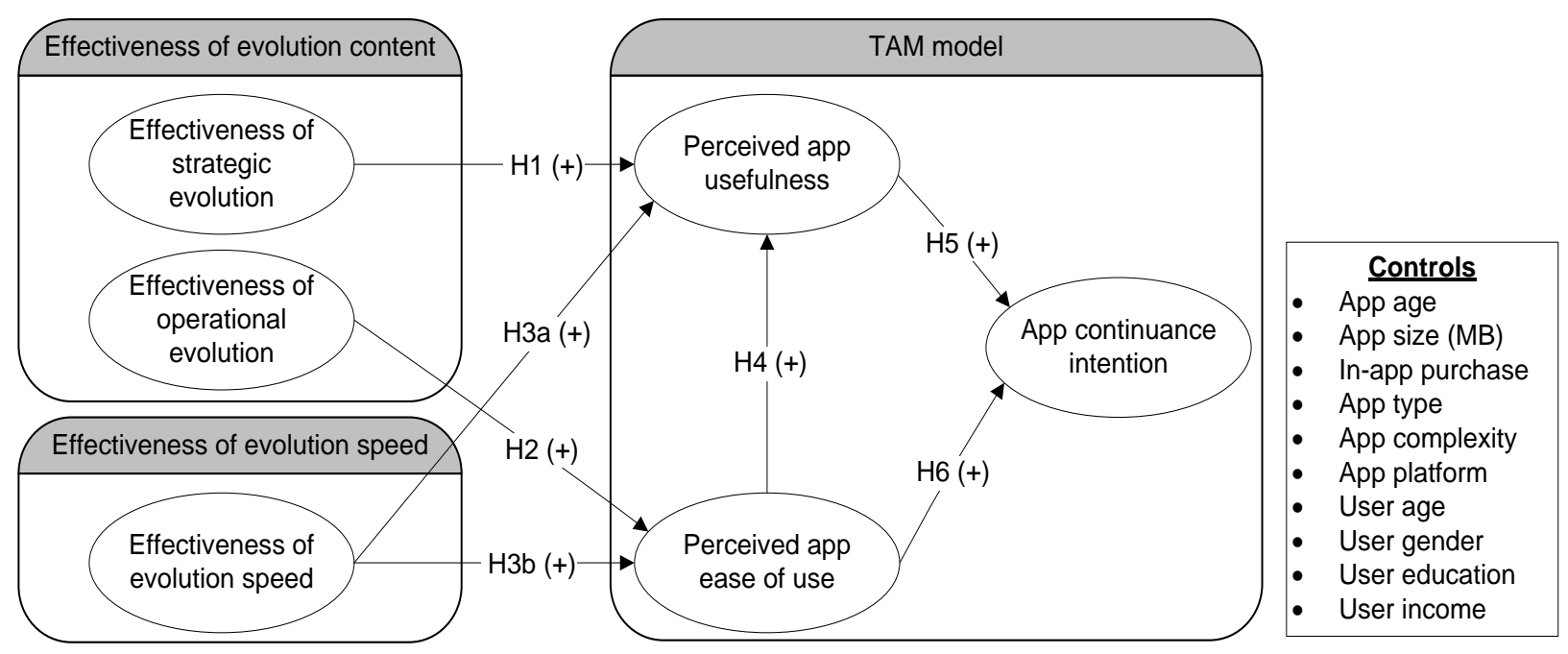

Figure 1. Research Model

Table 2. Main Construct Definitions and Sources

\begin{tabular}{|l|l|l|}
\hline \multicolumn{1}{|c|}{ Construct } & \multicolumn{1}{c|}{ Definition } & \multicolumn{1}{c|}{ Source } \\
\hline $\begin{array}{l}\text { Effectiveness of } \\
\text { strategic evolution }\end{array}$ & $\begin{array}{l}\text { User perceptions about the extent to which an app effectively } \\
\text { adds new features }\end{array}$ & $\begin{array}{l}\text { Adapted from Pavlou and } \\
\text { Gefen (2004) and Fang et } \\
\text { al. (2014) }\end{array}$ \\
\hline $\begin{array}{l}\text { Effectiveness of } \\
\text { operational evolution }\end{array}$ & $\begin{array}{l}\text { User perceptions about the extent to which an app effectively } \\
\text { refines existing features }\end{array}$ & $\begin{array}{l}\text { Adapted from Pavlou \& } \\
\text { Gefen (2004) and Fang et } \\
\text { al. (2014) }\end{array}$ \\
\hline $\begin{array}{l}\text { Effectiveness of } \\
\text { evolution speed }\end{array}$ & $\begin{array}{l}\text { User perceptions about the rate at which an app's developer(s) } \\
\text { release upgraded versions of it }\end{array}$ & $\begin{array}{l}\text { Adapted from Tiwana } \\
\text { (2015) }\end{array}$ \\
\hline $\begin{array}{l}\text { Perceived app } \\
\text { usefulness }\end{array}$ & $\begin{array}{l}\text { The degree to which an app user thinks that an app provides } \\
\text { useful functionalities }\end{array}$ & $\begin{array}{l}\text { Adapted from Deng, Turner, } \\
\text { Gehling, and Prince (2010) } \\
\text { and Venkatesh and Goyal } \\
\text { (2010) }\end{array}$ \\
\hline $\begin{array}{l}\text { Perceived app ease of } \\
\text { use }\end{array}$ & $\begin{array}{l}\text { The degree to which an app user thinks that using an app will be } \\
\text { free of effort }\end{array}$ & $\begin{array}{l}\text { Adapted from Venkatesh } \\
\text { and Goyal (2010) }\end{array}$ \\
\hline $\begin{array}{l}\text { App continuance } \\
\text { intention }\end{array}$ & An app user's intention to continue using the same app & $\begin{array}{l}\text { Adapted from Venkatesh } \\
\text { and Goyal (2010) }\end{array}$ \\
\hline
\end{tabular}

\subsection{The Role of Effectiveness of Evolution Content}

Strategic evolution and operational evolution have different focuses and can affect user perceptions differently. Through strategic evolution, an app can bring new features, such as new functionalities, components, and modules, to users. By effectively adding new features, an app can also maintain user interest and counteract negative perceptions about the app's functions and, thus, enhance the degree to which users perceive the app as useful. In addition, effectively adding new features can allow users to experimentally taste the app's presence and functions, which can solidify app users' impressions about the new version's functions. With these positive impressions, users are more likely to perceive the app as 
more useful. Moreover, competition in the app market never stops (Barnett, 2008; Robson, 2005). Many apps provide similar functionalities in the app market since original apps often have copycats (Wang et al., 2018). Users may compare features across similar apps in the market (Hamilton, Rust, \& Dev, 2017). If an app has fewer features than its competitors, users may perceive the app as less useful than its competitors. Also, if users find these newly added features ineffective (e.g., if they have bugs or useless functions), they may determine that the newly upgraded app does not meet their needs, which reduces the app's perceived usefulness. Thus, we propose:

H1: Effectiveness of strategic evolution positively relates to perceived app usefulness.

Apps usually suffer from operational issues, such as bugs and crash issues, due to coding mistakes, inadequate design logic, improper reuse of existing modules, schedule pressures that cause flaws in programming, and inadequate testing before launching to the market (Wong, Li, Laplante, \& Siok, 2017). Regular upgrades to a platform (i.e., Android or iOS) can also cause operational issues. Regular upgrades to a platform may cause some app features to stop working on an upgraded platform. These bugs and crashes cause users to exert more effort when using the app, which can reduce the extent to which they perceive the app as easy to use. Effective operational evolution refines existing features and improves the design. In addition, effective operational evolution reduces operational errors and solves crashes, which makes app easier to use with less effort and fewer difficulties. Thus, we propose:

H2: Effectiveness of operational evolution positively relates to perceived app ease of use.

\subsection{The Role of Effectiveness of Evolution Speed}

Effective evolution speed responds to changes in user preferences in a timely manner. Since the app market is highly dynamic with low barriers to entry, app developers will likely often receive a steady stream of feedback from users, competing apps, and opportunities due to external technological advances (Tiwana, 2015). Feedback from app users may include suggestions such as the functions they want or complaints about bugs and crashes. Incorporating these suggestions and addressing complaints quickly makes users feel that developers care about their concerns and value their opinions, which can increase the extent to which they perceive an app as useful and easy to use. Moreover, promptly incorporating features from competing apps into upgrades can enhance the extent to which users perceive an app as usefulness. In addition, emerging technologies often bring new ideas and opportunities to enrich an app and solve technical issues. Rapid evolution allows an app to incorporate the new ideas and opportunities offered by emerging technologies and, thereby, improve the app's usefulness in terms of functions and reduces user effort to operate it. However, too much and too frequent app evolution can burn out users (Webiotic, 2019) because they need time to assimilate the changes in each upgrade (Saffarizadeh et al., 2018). Therefore, developers should carefully time how they release new upgrades to meet user expectations. Accordingly, we propose that effectiveness of evolution speed can enhance perceived usefulness and ease of use. Thus,

H3a: Effectiveness of evolution speed positively relates to perceived app usefulness.

H3b: Effectiveness of evolution speed positively relates to perceived app ease of use.

\subsection{Perceived App Ease of Use, Perceived App Usefulness, and App Continuance Intention}

According to Davis (1989), PU focuses on the benefits that users gain from using a system while PEOU focuses on the effort they expend to use a system. When examining user behaviors in system adoption, Davis (1989) suggested that these two perceptions may not be independent but that PEOU can affect PU. Previous research has discussed this relationship in great detail (e.g., Lai \& Li, 2004; Agrebi \& Jallais, 2015; Ho, Ke, Liu \& Chau, 2020). We hypothesize that such a relationship applies to the app market. Generally speaking, if users find an app easy to use, they may have to put less effort into using it and be more likely to explore, appreciate, and enjoy different functions in it. The more effort users put into exploring, appreciating, and enjoying an app's different functions, the better the user experience, which leads to higher performance benefits from using the app. In turn, those performance benefits will lead to a higher PU, especially when better alternatives exist on the app market. Therefore, we propose:

H4: Perceived app ease of use positively relates to perceived app usefulness. 
Moreover, TAM posits that perceived usefulness and perceived ease of use determine intention to use (Davis, 1989) because 1) high perceived usefulness makes users believe that a positive use-performance relationship exists and 2) high perceived ease of use means "freedom from difficulty or great effort" (Davis, 1989, p. 320) and effort constitutes a limited resource that users may allocate to use or continue using a system (Venkatesh \& Davis, 2000; Venkatesh \& Goyal, 2010; Venkatesh et al., 2016). We believe such relationships exist in app content as well. We argue that users will form a positive opinion when they believe that an app 1) provides necessary functions to satisfy their goals (i.e., high level of usefulness) and 2) does not require too much time and effort to navigate for their goals (i.e., high level of ease of use). Based on the above arguments, we propose the following hypotheses:

H5: Perceived app usefulness positively relates to app continuance intention.

H6: Perceived app ease of use positively relates to app continuance intention.

\section{Research Design}

\subsection{Measurement Development}

We followed the process that MacKenzie, Podsakoff, and Podsakoff (2011) describe to develop the survey instrument. We first extensively reviewed the literature on TAM and app evolution. Whenever possible, we adopted or adapted existing validated measures to ensure the measurement items' quality. We treated all constructs as reflective indicators and measured the items using a seven-point Likert scale unless specified otherwise (see the Appendix).

To capture the "effectiveness" of app evolution (e.g., strategic evolution, operational evolution, and evolution speed), we adapted existing effectiveness measures from the IS literature (Pavlou \& Gefen 2004; Fang et al., 2014). Specifically, items for the effectiveness of strategic evolution capture whether users find newly added features useful, helpful, reliable, enjoyable, and practical. Items for the effectiveness of operational evolution capture whether the refined features can effectively reduce errors and smooth an app's operation. Items for the effectiveness of evolution speed capture whether an app's developer (or developers) upgrades an app at an appropriate, effective, fast, and successful speed to address customer requirements and environmental changes. We adopted items for perceived app usefulness, perceived app ease of use, and app continuance intention from the existing TAM literature (Abdullah et al., 2016; Deng et al., 2010; Venkatesh \& Goyal, 2010).

We asked four academic professionals in the IS field to review our initial questionnaire to assess content validity. In addition, we used a two-stage sorting process to validate the questions and identify ambiguous or inappropriately worded items in order to validate the various scales (Moore \& Benbasat, 1991). We asked four students to sort items into their corresponding constricts over two rounds. They correctly placed 90 percent and 100 percent of the items in their corresponding constructs in the first and second rounds, respectively. We revised items based on comments we received from the academic professionals and sorters. We pilot tested the revised questionnaire with 104 students at two major universities in the United States (US). The items covaried with each other and exhibited high internal consistency or reliability (Cronbach's alpha > .80) (Petter, Straub, \& Rai, 2007) and, thus, provided empirical support to our decision to model these constructs as reflective. We followed established procedures to examine measurement items' validity. The results evidenced good convergent and discriminant validity. The pilot test results indicated that the items exhibited good quality and that we could use them in large-scale data collection.

We included ten control variables in the model in order to exclude potential alternative explanations due to individual differences and app differences. We controlled for users' age, gender, income level, and education level as these factors may affect users' app continuance intention (Correa, Hinsley, \& De Zuniga, 2010). In addition, the existing literature indicates that app characteristics may also affect app performance (Ghose \& Han, 2014; Liu et al., 2014; Tiwana, 2015). We collected subjective data for app complexity and objective data for app age, app size, app type, in-app purchase, and app platform using app links that respondents provided and controlled for their effects on app continuance intention.

\subsection{Data Collection}

We collected self-reported survey data from app users (Google Play and Apple's App Store) to test the proposed research model. We used Amazon's Mechanical Turk to recruit potential respondents in the U.S. 
app market because Mechanical Turk yields comparable samples to samples that one collects from students and individual user panels in the US (Liu \& Tang, 2018; Steelman, Hammer, \& Limayem, 2014). We asked respondents to recall their use experience with an app on Google Play or Apple's App Store in the most recent three months. To ensure accuracy, we asked respondents to provide the app name and Web link to the app. We provided nominal incentives to encourage participation.

In total, 442 users participated in the study, but we disqualified 143 because they failed to pass our screening questions and/or to provide a valid app website link. After removing these responses, 299 valid responses remained (for a $67.65 \%$ response rate). Compared to extant studies on apps (Lim, Bentley, Kanakam, Ishikawa, \& Honiden, 2014; Rayle, Shaheen, Chan, Dai, \& Cervero, 2014), we obtained an appropriate response rate. We provide the respondent demographics in Table 3.

To ensure that non-response bias did not pose a concern in this study, we conducted an individual t-test on main constructs' means by examining early and late respondents. We examined the first 50 respondents and the last 50 respondents. Results indicated that non-respondent bias had a minimal impact in this study.

Table 3. Respondent Demographics

\begin{tabular}{|c|c|c|c|c|c|}
\hline Respondent age & N & Percent & Respondent gender & N & Percent \\
\hline Under 21 & 39 & $13.04 \%$ & Female & 114 & $38.13 \%$ \\
\hline $21-30$ & 94 & $31.44 \%$ & Male & 185 & $61.87 \%$ \\
\hline $31-40$ & 113 & $37.79 \%$ & Respondent annual income & $\mathbf{N}$ & Percent \\
\hline $41-50$ & 36 & $12.04 \%$ & Below $\$ 25,000$ & 108 & $36.12 \%$ \\
\hline Older than 50 & 17 & $5.69 \%$ & $\$ 25,000-49,999$ & 94 & $31.44 \%$ \\
\hline Respondent education level & $\mathbf{N}$ & Percent & $\$ 50,000-74,999$ & 58 & $19.40 \%$ \\
\hline High school diploma & 102 & $34.11 \%$ & $\$ 75,000-99,999$ & 18 & $6.02 \%$ \\
\hline Associate degree & 43 & $14.38 \%$ & $\$ 100,000+$ & 18 & $6.02 \%$ \\
\hline Bachelor degree & 117 & $39.13 \%$ & & & \\
\hline Graduate degree & 37 & $12.37 \%$ & & & \\
\hline
\end{tabular}

\section{Analysis and Results}

Researchers consider partial least squares (PLS) an appropriate method when one seeks to predict and develop theory and one uses a complex model (Hair, Ringle, \& Sarstedt, 2011; Hair, Hult, Ringle, \& Sarstedt, 2016). Thus, we used SmartPLS to validate our measurements and test our model following the approach that Hair et al. (2016) and Ringle, Wende, and Becker (2015) outline.

\subsection{Evaluation of Overall Fit of the Saturated Model}

To evaluate the overall fit of the saturated model, we examined the standardized root mean squared residual (SRMR), unweighted least squares discrepancy ( $\left.d_{U L S}\right)$, and geodesic discrepancy $\left(d_{G}\right)$ (Benitez, Henseler, Castillo, \& Schuberth, 2020; Hair et al., 2016; Henseler et al., 2014). Table 4 reports the values of the discrepancy measures and 99 percent quantiles of their corresponding reference distribution. The value of the SRMR did not exceed the recommend threshold value 0.08 , and all discrepancy measures did not exceed the 99 percent quantile of their reference distribution, which indicates the model exhibited good fit.

Table 4. Results of the Overall Saturated Model Fit Evaluation

\begin{tabular}{|c|c|c|c|c|}
\hline \multirow{2}{*}{ Discrepancy } & \multicolumn{4}{|c|}{ Overall saturated model fit evaluation } \\
\cline { 2 - 5 } & Value & $\mathbf{H I}_{\mathbf{9 5}}$ & $\mathbf{H l}_{99}$ & Conclusion \\
\hline SRMR & 0.039 & 0.041 & 0.074 & Supported \\
\hline $\mathrm{d}_{\mathrm{gLS}}$ & 1.251 & 1.565 & 1.724 & Supported \\
\hline $\mathrm{d}_{\mathrm{G}}$ & 0.793 & 0.947 & 1.018 & Supported \\
\hline
\end{tabular}




\subsection{Measurement Validation}

First, we conducted an exploratory factor analysis (EFA) and extracted factors through principal component analysis (PCA). Two items of app continuance intention and one item of app complexity that had low loadings (less than 0.500) on the appropriate factor and we removed high cross-loadings from the remaining measurement assessments and model testing (MacKenzie et al., 2011). Table 5 reports the results from the exploratory factor analysis, and Table 6 presents the sample's descriptive statistics, correlation, and square root of average variance extracted (AVE) values. We examined each construct's internal consistency and convergent and discriminant validity (Henseler, Ringle, \& Sarstedt, 2015; MacKenzie et al., 2011). The appendix shows that Cronbach's $\alpha$ for each latent variable exceeded 0.70 , which suggests good reliability. All the retained items had loadings above the recommended cutoff (i.e., 0.70) (see Table 5) and the average variance extracted (AVE) for each construct exceeded the recommended level (i.e., 0.50) (see Table 6), which suggests good convergent validity. Also, all items had a much higher loading on their respective constructs than on other constructs (see Table 5) and the square root of AVE for each construct exceeded the correlation between each pair of constructs in the model (see Table 6). In addition, HTMT ratio values also did not exceed 0.85 (see Table 7 ). These three results indicate good discriminant validity.

To check for the existence of multicollinearity, we computed the variance inflation factor (VIF) values for all constructs. The highest VIF was 1.429, well below the acceptable threshold (i.e., 10.0), which indicates that multicollinearity did not likely pose an issue (Cohen, Cohen, West, \& Aiken, 2003).

Table 5. Exploratory Factor Analysis Results

\begin{tabular}{|c|c|c|c|c|c|c|c|c|}
\hline \multirow{2}{*}{ Items } & \multicolumn{7}{|c|}{ Item loadings and cross loadings } \\
\cline { 2 - 9 } & PU & EOU & ESE & ACI & EES & EOE & DT & AC \\
\hline PU_9 & $\mathbf{0 . 8 2 6}$ & 0.118 & 0.026 & 0.021 & 0.108 & 0.121 & 0.040 & -0.023 \\
\hline PU_8 & $\mathbf{0 . 8 1 4}$ & 0.020 & 0.046 & -0.021 & 0.108 & 0.091 & 0.011 & 0.007 \\
\hline PU_7 & $\mathbf{0 . 7 8 2}$ & 0.137 & 0.119 & 0.030 & 0.087 & 0.139 & 0.027 & -0.032 \\
\hline PU_6 & $\mathbf{0 . 7 5 6}$ & 0.182 & 0.095 & 0.226 & 0.086 & 0.132 & 0.027 & 0.008 \\
\hline PU_1 & $\mathbf{0 . 7 2 6}$ & 0.017 & 0.132 & 0.280 & 0.039 & -0.010 & 0.072 & 0.067 \\
\hline PU_4 & $\mathbf{0 . 7 1 1}$ & 0.294 & 0.090 & 0.155 & 0.055 & 0.129 & -0.100 & -0.057 \\
\hline PU_2 & $\mathbf{0 . 6 9 0}$ & 0.066 & 0.029 & 0.109 & 0.023 & 0.013 & 0.003 & 0.046 \\
\hline PU_3 & $\mathbf{0 . 6 7 9}$ & -0.067 & 0.164 & -0.011 & 0.146 & -0.134 & 0.072 & 0.101 \\
\hline PU_5 & $\mathbf{0 . 6 6 7}$ & 0.247 & 0.065 & 0.234 & 0.133 & 0.154 & 0.088 & -0.044 \\
\hline EOU_4 & 0.097 & $\mathbf{0 . 8 4 0}$ & 0.112 & 0.052 & 0.041 & 0.068 & 0.036 & -0.067 \\
\hline EOU_3 & 0.116 & $\mathbf{0 . 8 2 2}$ & 0.088 & 0.173 & 0.100 & 0.107 & 0.018 & -0.038 \\
\hline EOU_5 & 0.148 & $\mathbf{0 . 8 1 9}$ & 0.057 & 0.085 & 0.173 & 0.112 & 0.032 & -0.059 \\
\hline EOU_6 & 0.118 & $\mathbf{0 . 8 1 4}$ & 0.107 & 0.129 & 0.123 & 0.130 & -0.003 & -0.063 \\
\hline EOU_2 & 0.075 & $\mathbf{0 . 7 6 4}$ & 0.016 & 0.106 & 0.150 & 0.089 & 0.004 & -0.072 \\
\hline EOU_1 & 0.186 & $\mathbf{0 . 7 3 1}$ & 0.136 & 0.176 & 0.042 & 0.132 & 0.057 & -0.066 \\
\hline ESE_2 & 0.091 & 0.108 & $\mathbf{0 . 8 4 4}$ & 0.078 & 0.145 & 0.239 & -0.031 & -0.007 \\
\hline ESE_5 & 0.161 & 0.145 & $\mathbf{0 . 8 1 5}$ & -0.015 & 0.127 & 0.213 & -0.040 & -0.060 \\
\hline ESE_1 & 0.096 & 0.109 & $\mathbf{0 . 7 9 2}$ & 0.057 & 0.143 & 0.271 & -0.023 & -0.008 \\
\hline ESE_4 & 0.083 & 0.125 & $\mathbf{0 . 7 7 6}$ & 0.015 & 0.190 & 0.146 & 0.050 & 0.070 \\
\hline ESE_3 & 0.193 & 0.005 & $\mathbf{0 . 7 3 7}$ & -0.056 & 0.234 & 0.168 & 0.103 & -0.007 \\
\hline ACI_1 & 0.176 & 0.116 & -0.039 & $\mathbf{0 . 8 7 8}$ & 0.045 & 0.046 & 0.017 & -0.067 \\
\hline ACI_4 & 0.105 & 0.162 & -0.038 & $\mathbf{0 . 8 5 0}$ & 0.018 & 0.102 & -0.018 & -0.023 \\
\hline ACI_3 & 0.113 & 0.133 & 0.035 & $\mathbf{0 . 8 3 4}$ & 0.066 & 0.037 & 0.029 & -0.076 \\
\hline ACI_2 & 0.072 & 0.184 & 0.017 & $\mathbf{0 . 7 6 0}$ & 0.002 & 0.088 & 0.009 & -0.117 \\
\hline ACI_5 & 0.218 & 0.049 & 0.093 & $\mathbf{0 . 7 3 6}$ & 0.103 & -0.009 & 0.039 & -0.030 \\
\hline
\end{tabular}


Table 5. Exploratory Factor Analysis Results

\begin{tabular}{|c|c|c|c|c|c|c|c|c|}
\hline EES_3 & 0.159 & 0.160 & 0.236 & 0.017 & $\mathbf{0 . 8 3 8}$ & 0.100 & 0.074 & 0.027 \\
\hline EES_4 & 0.184 & 0.164 & 0.194 & 0.080 & $\mathbf{0 . 8 3 4}$ & 0.171 & 0.081 & 0.013 \\
\hline EES_2 & 0.153 & 0.178 & 0.192 & 0.066 & $\mathbf{0 . 8 2 9}$ & 0.182 & 0.051 & -0.055 \\
\hline EES_1 & 0.162 & 0.144 & 0.238 & 0.105 & $\mathbf{0 . 7 8 0}$ & 0.148 & 0.107 & -0.057 \\
\hline EOE_4 & 0.158 & 0.144 & 0.285 & 0.070 & 0.183 & $\mathbf{0 . 8 0 8}$ & 0.058 & 0.013 \\
\hline EOE_1 & 0.073 & 0.169 & 0.269 & 0.089 & 0.156 & $\mathbf{0 . 7 8 9}$ & 0.046 & -0.006 \\
\hline EOE_2 & 0.099 & 0.165 & 0.284 & 0.127 & 0.163 & $\mathbf{0 . 7 7 6}$ & -0.018 & -0.030 \\
\hline EOE_3 & 0.180 & 0.207 & 0.329 & 0.020 & 0.129 & $\mathbf{0 . 7 4 9}$ & 0.020 & -0.009 \\
\hline DT_1 & 0.077 & 0.050 & 0.024 & 0.017 & 0.091 & 0.042 & $\mathbf{0 . 9 2 6}$ & -0.003 \\
\hline DT_3 & -0.031 & 0.013 & -0.011 & 0.108 & 0.056 & 0.001 & $\mathbf{0 . 9 0 7}$ & 0.053 \\
\hline DT_2 & 0.112 & 0.047 & 0.033 & -0.056 & 0.095 & 0.033 & $\mathbf{0 . 9 0 2}$ & 0.009 \\
\hline AC_3 & 0.047 & -0.080 & -0.043 & -0.097 & -0.008 & -0.001 & -0.030 & $\mathbf{0 . 9 3 0}$ \\
\hline AC_2 & 0.037 & -0.033 & 0.026 & -0.104 & -0.048 & -0.044 & 0.058 & $\mathbf{0 . 9 0 4}$ \\
\hline AC_1 & 0.006 & -0.198 & 0.014 & -0.080 & 0.003 & 0.022 & 0.032 & $\mathbf{0 . 9 0 1}$ \\
\hline NT
\end{tabular}

Notes: extraction method: principal component analysis. Rotation method: varimax with kaiser normalization.

PU: perceived app usefulness; EOU: perceived app ease of use; ACI: app continuance intention; ESE: effectiveness of strategic evolution; EES: effectiveness of evolution speed; EOE: effectiveness of operational evolution; AC: app complexity; DT: deposition toward trust.

Table 6. Descriptive Statistics, Correlations, and Square Roots of Average Variance Extracted ( $=299)$

\begin{tabular}{|c|c|c|c|c|c|c|c|c|c|c|c|c|c|c|c|c|}
\hline & 1 & 2 & 3 & 4 & 5 & 6 & 7 & 8 & 9 & 10 & 11 & 12 & 13 & 14 & 15 & 16 \\
\hline 1) ESE & 0.854 & & & & & & & & & & & & & & & \\
\hline 2) EOE & $0.596^{* *}$ & 0.883 & & & & & & & & & & & & & & \\
\hline 3) EES & $0.493^{* *}$ & $0.458^{\star \star}$ & 0.900 & & & & & & & & & & & & & \\
\hline 4) PU & $0.306^{* *}$ & $0.307^{\star *}$ & $0.360^{\star *}$ & 0.769 & & & & & & & & & & & & \\
\hline 5) EOU & $0.281^{* *}$ & $0.391^{* *}$ & $0.368^{\star *}$ & $0.317^{* *}$ & 0.839 & & & & & & & & & & & \\
\hline 6) $\mathrm{AC}$ & -0.022 & -0.052 & -0.058 & 0.012 & $-0.198^{\star *}$ & 0.924 & & & & & & & & & & \\
\hline 7) $\mathrm{ACl}$ & 0.104 & $0.210^{* \star}$ & $0.199^{\star *}$ & $0.316^{* *}$ & $0.329^{* *}$ & $-0.187^{\star \star}$ & 0.843 & & & & & & & & & \\
\hline 8) UA & 0.066 & 0.065 & 0.008 & $0.238^{* *}$ & 0.066 & $-0.132^{*}$ & 0.065 & - & & & & & & & & \\
\hline 9) UE & 0.093 & 0.091 & 0.081 & $0.259^{* *}$ & 0.038 & -0.007 & -0.059 & $0.344^{* *}$ & - & & & & & & & \\
\hline 10) UG & 0.020 & 0.045 & 0.035 & 0.001 & -0.013 & -0.062 & 0.085 & $0.126^{*}$ & -0.096 & - & & & & & & \\
\hline 11) UI & 0.065 & 0.085 & 0.006 & $0.138^{*}$ & 0.048 & 0.024 & -0.016 & $0.391^{\star *}$ & $0.408^{\star *}$ & 0.035 & - & & & & & \\
\hline 12) $A T$ & -0.072 & -0.110 & 0.003 & $0.176^{* *}$ & 0.073 & 0.030 & $0.126^{*}$ & -0.082 & 0.026 & 0.015 & -0.030 & - & & & & \\
\hline 13) AS & 0.105 & 0.066 & -0.025 & $-0.148^{*}$ & 0.008 & 0.091 & -0.011 & -0.123 & $-0.165^{\star}$ & -0.005 & -0.010 & -0.140 & - & & & \\
\hline 14) IAP & 0.006 & 0.036 & -0.04 & -0.024 & -0.068 & 0.073 & -0.059 & 0.028 & -0.007 & 0.113 & 0.001 & $-0.353^{* *}$ & $0.169^{*}$ & - & & \\
\hline 15) AP & $0.116^{*}$ & 0.082 & 0.004 & $0.189^{* *}$ & $0.119^{*}$ & -0.068 & 0.048 & $0.357^{\star \star}$ & $0.235^{\star \star}$ & $-0.116^{*}$ & 0.072 & 0.033 & $-0.522^{* *}$ & -0.009 & - & \\
\hline 16) $\mathrm{AA}$ & -0.029 & $-0.0137^{\star}$ & 0.049 & 0.017 & 0.021 & 0.045 & 0.047 & $-0.147^{*}$ & -0.100 & 0.058 & -0.003 & $.466^{\star \star}$ & 0.089 & $-0.245^{\star \star}$ & $-0.294^{* *}$ & - \\
\hline Mean & 5.609 & 5.656 & 5.53 & 5.828 & 6.317 & 2.75 & 4.684 & 2.659 & 2.298 & 1.381 & 2.135 & 0.88 & 116.435 & 1.605 & 1.405 & 82.391 \\
\hline SD & 1.042 & 1.071 & 1.093 & 0.925 & 0.689 & 1.138 & 0.492 & 1.035 & 1.069 & 0.487 & 1.157 & 0.326 & 112.836 & 0.49 & 0.498 & 30.991 \\
\hline
\end{tabular}

${ }^{* *}$ Correlation significant at the 0.01 level (2-tailed). ${ }^{*}$ Correlation significant at the 0.05 level (2-tailed).

Note: the diagonals are the square root of the average variance extracted (AVE) for multi-item constructs.

ESE: effectiveness of strategic evolution; EOE: effectiveness of operational evolution; EES: effectiveness of evolution speed; PU: perceived app usefulness; EOU: perceived app ease of use; AC: app complexity; ACI: app continuance intention; UA: user age; UE: user education; UG: user gender; UI: user income; AT: app type; AS: app size; IAP: in-app purchase; AP: app platform; AA: app age 
Table 7. Heterotrait-Monotrait Ratio of Correlations (HTMT) Results

\begin{tabular}{|l|c|c|c|c|c|c|c|}
\hline & 1 & 2 & 3 & 4 & 5 & 6 & 7 \\
\hline 1) Effectiveness of strategic evolution & - & & & & & & \\
\hline 2) Effectiveness of operational evolution & 0.660 & - & & & & & \\
\hline 3) Effectiveness of evolution speed & 0.538 & 0.502 & - & & & & \\
\hline 4) Perceived app usefulness & 0.336 & 0.348 & 0.394 & - & & & \\
\hline 5) Perceived app ease of use & 0.309 & 0.430 & 0.403 & 0.366 & - & & \\
\hline 6) App complexity & 0.055 & 0.058 & 0.067 & 0.071 & 0.218 & - & \\
\hline 7) App continuance intention & 0.116 & 0.232 & 0.214 & 0.365 & 0.364 & 0.207 & - \\
\hline
\end{tabular}

We assessed common method bias after collecting data using two analyses that IS studies have outlined (Bush, Tiwana, \& Rai, 2010; Liu, Armstrong, \& Riemenschneider, 2018). First, we used Harman's single factor test to assess common method bias (Harman, 1976; Podsakoff, MacKenzie, Lee, \& Podsakoff, 2003). Eight factors emerged from the dataset that accounted for 73.82 percent of the variance, while first factor explained 27.45 percent of the variance. Then, we performed a partial correlation test using disposition to trust, a consistent tendency to willingly trust others (Mcknight, Cummings, \& Chervany, 1998), as a marker variable to evaluate the impact that common method bias had on the observed relationships between constructs (Lindell \& Whitney, 2001). We correlated marker variable with the principal constructs and used the smallest positive value to calculate the partial-correlation. The results indicated that changes in the partial correlation were nonsignificant. These two tests suggested that common method bias did not likely have a significant impact in our dataset.

\subsection{Structural Model}

We used a standard bootstrap resampling procedure (5,000 samples) to evaluate the paths' significance (Hair et al., 2016). We tested the path coefficients' significance using a two-tailed t-test. We provide the results for the structural model in Figure 2. According to the results, the model explained 20.2 percent of the variance in perceived app ease of use, 21.1 percent of the variance in perceived app usefulness, and 22.3 percent of the variance in app continuance intention. Among the ten control variables, app complexity and user education level had significant negative impacts on app continuance intention, which indicates that apps with a complex structure will reduce app continuance intention, and users who have a high education level are less likely to continue using an app.

As Figure 2 shows, we found support for every hypothesis we proposed:

- $\quad$ An increase in the effectiveness of strategic evolution was positively associated with higher perceived app usefulness $(\mathrm{H} 1: \beta=0.143, t=2.099, p<0.05)$ and an increase in effectiveness of operational evolution was positively associated with higher perceived app ease of use (H2: $\beta$ $=0.284, \mathrm{t}=3.610, \mathrm{p}<0.001)$.

- An increase in the effectiveness of evolution speed was positively related to both perceived app usefulness $(\mathrm{H} 3 \mathrm{a}: \beta=0.204, \mathrm{t}=2.952, \mathrm{p}<0.01)$ and perceived app ease of use $(\mathrm{H} 3 \mathrm{~b}: \beta=$ $0.241, \mathrm{t}=3.454, \mathrm{p}<0.001)$.

- An increase in perceived app ease of use was positively associated with perceived app usefulness ( $\mathrm{H} 4: \beta=0.250, t=3.773, p<0.001)$.

- $\quad$ An increase in perceived app usefulness $(H 5: \beta=0.301, t=4.497, p<0.001)$ and an increase in perceived app ease of use $(\mathrm{H} 6: \beta=0.195, t=2.575, p<0.01)$ were positively related to app continuance intention. 


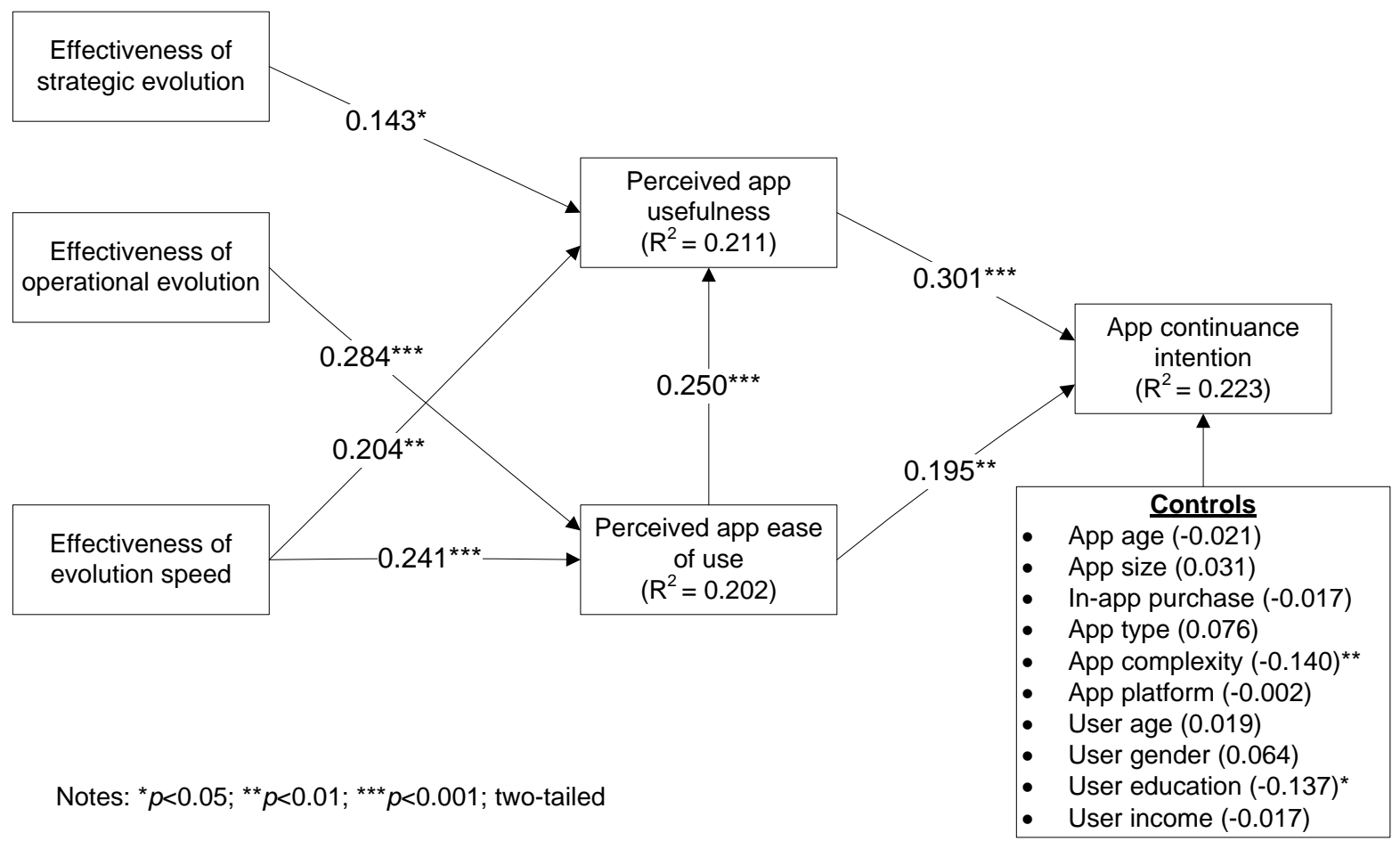

Figure 2. Model Results

\subsection{Robustness Check}

We conducted three tests to check the test results' robustness. To evaluate the stability of the path coefficients' significance, we first tested the model using a different number of samples in the bootstrap resampling procedure (6,000 samples and 7,000 samples). We found consistent significance levels for each path coefficient (see Table 8).

Second, we tested two alternative models to check the proposed research model's robustness. We tested the potential linkage between effectiveness of strategic evolution and PEOU $(\beta=-0.005, t=0.059)$ and the linkage between effectiveness of operational evolution and $P U(\beta=0.107, t=1.288)$. In addition, we also tested to see whether effectiveness of strategic evolution $(\beta=-0.111, t=1.295)$, effectiveness of operational evolution $(\beta=0.100, t=1.342)$, and effectiveness of evolution speed $(\beta=0.028, t=0.326)$ had a direct impact on app continuance intention. These additional paths were not significant, and including them did not change our proposed model.

Finally, even though we did not propose mediation effects in this study, the research model embedded such effects. Thus, we conducted a Sobel test to examine whether perceived app usefulness and perceived app ease of use served as mediators between effectiveness of app evolution and app continuance intention (Sobel, 1982). The Sobel tests produced completely significant statistics $(p<0.05)$, which indicates that perceived app usefulness and perceived app ease of use acted as mediators among effectiveness of strategic evolution, effectiveness of operational evolution, effectiveness of evolution speed, and app continuance intention.

Table 8. Robustness Check Results (Bootstrapping

\begin{tabular}{|c|c|c|c|}
\hline Bootstrapping & $\mathbf{5 , 0 0 0}$ & $\mathbf{6 , 0 0 0}$ & $\mathbf{7 , 0 0 0}$ \\
\hline Path & T-value & T-value & T-value \\
\hline App age -> app continuance intention & 0.361 & 0.355 & 0.359 \\
\hline App complexity -> app continuance intention & $\mathbf{2 . 8 7 8}$ & $\mathbf{2 . 8 1 7}$ & $\mathbf{2 . 8 5 8}$ \\
\hline Perceived app ease of use -> app continuance intention & $\mathbf{2 . 5 7 5}$ & $\mathbf{2 . 5 2 7}$ & $\mathbf{2 . 5 2 4}$ \\
\hline Perceived app ease of use -> app continuance intention & $\mathbf{3 . 7 7 3}$ & $\mathbf{3 . 7 5 4}$ & $\mathbf{3 . 8 1 8}$ \\
\hline App platform -> app continuance intention & 0.031 & 0.031 & 0.030 \\
\hline
\end{tabular}


Table 8. Robustness Check Results (Bootstrapping

\begin{tabular}{|c|c|c|c|}
\hline App size -> app continuance intention & 0.411 & 0.407 & 0.406 \\
\hline App type -> app continuance intention & 1.128 & 1.115 & 1.127 \\
\hline Perceived app usefulness -> app continuance intention & $\mathbf{4 . 4 9 7}$ & $\mathbf{4 . 4 6 1}$ & $\mathbf{4 . 4 7 3}$ \\
\hline Effectiveness of evolution speed -> perceived app ease of use & $\mathbf{3 . 4 5 4}$ & $\mathbf{3 . 4 9 8}$ & $\mathbf{3 . 4 5 7}$ \\
\hline Effectiveness of evolution speed -> perceived app usefulness & $\mathbf{2 . 9 5 2}$ & $\mathbf{2 . 9 5 3}$ & $\mathbf{2 . 9 6 6}$ \\
\hline Effectiveness of operational evolution -> perceived app ease of use & $\mathbf{3 . 6 1 0}$ & $\mathbf{3 . 6 6 4}$ & $\mathbf{3 . 6 8 0}$ \\
\hline Effectiveness of strategic evolution -> perceived app usefulness & $\mathbf{2 . 0 9 9}$ & $\mathbf{2 . 1 0 3}$ & $\mathbf{2 . 0 9 7}$ \\
\hline In-app purchase - > app continuance intention & 0.325 & 0.324 & 0.332 \\
\hline User age -> app continuance intention & 0.327 & 0.324 & 0.327 \\
\hline User education -> app continuance intention & $\mathbf{2 . 3 5 3}$ & $\mathbf{2 . 3 1 0}$ & $\mathbf{2 . 3 7 1}$ \\
\hline User gender -> app continuance intention & 1.177 & 1.173 & 1.191 \\
\hline User income -> app continuance intention & 0.257 & 0.254 & 0.254 \\
\hline
\end{tabular}

\section{Discussions}

Building on the TAM and app evolution, we developed a research model to reveal the influence that effectiveness of app evolution has on user perceived app usefulness, ease of use, and app continuance intention.

\subsection{Research and Managerial Implications}

Two research implications emerge from this study. First, we contribute to the app evolution literature by opening up the black box of app evolution content and taking a user perspective to examine how the different aspects of app evolution affect user continuance. Specifically, we draw on the app evolution literature to identify that evolution content should be an equally, if not more, important aspect of app evolution to evolution speed. By further conducting a content analysis of different apps' evolution history, we identified two types of evolution content: strategic evolution and operational evolution. By classifying app evolution's aspects in such a nuanced way, we extend the app evolution literature and advance scholarly understanding about app evolution's multi-dimensional nature. Moreover, taking users as the stakeholders who can determine whether they want to continue using an app or not, we complement existing studies that mainly examine app evolution from the developer perspective (Agarwal \& Tiwana, 2015; Tiwana, 2015). Following established procedures (MacKenzie et al., 2011), we developed measurement items to capture the effectiveness of strategic evolution, effectiveness of operational evolution, and effectiveness of evolution speed. The empirical results revealed the different impact that these app evolution aspects had on shaping users' PEOU and PU. Specifically, we found that the effectiveness of strategic evolution positively influenced PU, while the effectiveness of operational evolution positively influenced PEOU. In addition, the effectiveness of evolution speed had a positive and direct impact on both PU and PEOU. By delineating the different impacts that evolution content and evolution speed have, this study provides a comprehensive understanding of app evolution on app continuance use from the user perspective.

Second, in this study, we extend the technology acceptance literature by integrating the app evolution perspective with the traditional TAM. Unlike traditional information technology and systems in which continuous use often constitutes a one-time decision, such a decision-making process can happen every time an app evolves. The app evolution perspective provides a theoretical lens to explore app factors that are progressive in nature to the continuous use of evolvable systems such as apps. We empirically show that app evolution effectiveness can foster a user's continuance intention by improving PEOU and PU. Therefore, with this study, we answer calls to use a sound theory and method to identify PEOU's and PU's antecedents (Bagozzi, 2007; Venkatesh et al., 2016) and, thus, extend the TAM to explain the continuance intention for evolvable systems and applications.

This study also has several important managerial implications for developers. Perceived app usefulness and ease of use still play important roles in influencing app continuance intention in the app market context. The effectiveness of app evolution (strategic evolution, operational evolution, and evolution 
speed) can influence these user perceptions. Understanding factors that influence app continuance intention can help developers retain users and gain profit. The efforts made to effectively evolve an app both in content and in speed can result in a positive change in the degree to which users perceive an app as useful and easy to use. Developers should also notice the varying impact that different app evolution aspects have on PU and PEOU. By deploying app evolution effectively, developers can influence app users to continuously use their apps and maximize their profits.

\subsection{Limitation and Future Research}

This study contains several limitations. First, we draw on original TAM's core components to capture this influential theory's essence. While this parsimonious approach meant we could remain focused and explore the effect that mobile app development's progressive impact (evolution) has on users' intentions to continue to use an app, we acknowledge that alternative acceptance models and theories (e.g., TAM2, UTAUT, and innovation diffusion theory) may provide other possible explanations. Future research could draw on these alternative models or theories to examine how the effectiveness of app evolution can affect other factors (e.g., app complexity, observability, compatibility) related to app continuous use. Second, we examined the three evolutionary constructs with cross-sectional survey data in which the respondent judges these evolution aspects as a totality. If researchers accessed longitudinal data, they could examine operational and strategic evolution as they occur to see if a feedback loop between these two evolution types exists and how their interplay changes app continuance intention. A longitudinal research design could also mitigate reverse causality's impact. In addition, researchers could conduct a multi-method study with case or empirical data to check our results' robustness. Third, researchers could further enrich our proposed model. For example, platforms also evolve, and how platform evolution affects the relationships that we propose in this study could be an interesting direction to follow. Finally, app evolution constitutes an iterative process that needs both developers' and users' participation. On one hand, developers collect user feedback on both an app's PEOU and PU, decide on the evolution content and speed, and hope to keep users continuously using the app. On the other hand, users evaluate how effectively the app evolves, form their PEOU and PU, and decide whether they want to keep using an app or not. We examine this iterative process only from the user perspective. Future research could take the developer or both perspectives to more comprehensively explain the role that effectiveness of app evolution plays in app continuance intention.

\section{Conclusion}

The rise of platform-centric ecosystems creates a highly dynamic app market. Given that many developers and organizations (especially small businesses and startups with limited resources) largely generate app revenue from users using their apps, they need to ensure they can convince users to continuously use them. App evolution has been treated as an important factor that drives app performance. Previous literature has focused on app evolution from the developer perspective while ignoring the role of app evolution from the app user perspective.

To address the research gap, we focus on the effectiveness of app evolution (content and speed) from the user standpoint and propose a research model to explore the relationship between effectiveness of app evolution and app continuous intention. Using subjective data collected from app users and objective data collected from Google Play, we reveal the intertwined relationships among effectiveness of app evolution, perceived app usefulness, perceived app ease of use, and app continuance intention. These findings can help developers understand the role that effectiveness of app evolution plays in app continuance intention. 


\section{References}

Abdullah, F., Ward, R., \& Ahmed, E. (2016). Investigating the influence of the most commonly used external variables of TAM on students' perceived ease of use (PEOU) and perceived usefulness (PU) of e-portfolios. Computers in Human Behavior, 63, 75-90.

Adjust. (2020). Active user / definition. Retrieved from https://www.adjust.com/glossary/active-user/

Agarwal, R., \& Tiwana, A. (2015). Evolvable systems: Through the looking glass of IS. Information Systems Research, 26(3), 473-479.

Agrebi, S., \& Jallais, J. (2015). Explain the intention to use smartphones for mobile shopping. Journal of Retailing and Consumer Services, 22, 16-23.

Bagozzi, R. P. (2007). The legacy of the technology acceptance model and a proposal for a paradigm shift. Journal of the Association for Information Systems, 8(4), 244-254.

Barnett, W. P. (2008). The red queen among organizations: How competitiveness evolves. Princeton, NJ: Princeton University Press.

Benitez, J., Henseler, J., Castillo, A., \& Schuberth, F. (2020). How to perform and report an impactful analysis using partial least squares: Guidelines for confirmatory and explanatory IS research. Information \& Management, 57(2), 103-168.

Bush, A. A., Tiwana, A., \& Rai, A. (2010). Complementarities between product design modularity and IT infrastructure flexibility in IT-enabled supply chains. IEEE Transactions on Engineering Management, 57(2), 240-254.

Carare, O. (2012). The impact of bestseller rank on demand: Evidence from the app market. International Economic Review, 53(3), 717-742.

Chen, L., Meservy, T. O., and Gillenson, M. 2012. Understanding information systems continuance for information-oriented mobile applications. Communications of the Association for Information Systems, 30(1), 127-146.

Chiu, C. M., \& Wang, E. T. (2008). Understanding Web-based learning continuance intention: The role of subjective task value. Information \& Management, 45(3), 194-201.

Cho, J. (2016). The impact of post-adoption beliefs on the continued use of health apps. International Journal of Medical Informatics, 87, 75-83.

Claussen, J., Kretschmer, T., \& Mayrhofer, P. (2013). The effects of rewarding user engagement: The case of facebook apps. Information Systems Research, 24(1), 186-200.

Cohen, J., Cohen, P., West, S. G., \& Aiken, L. S. (2003). Applied multiple regression/correlation analysis for the behavioral sciences (3rd ed). Mahwah, NJ: Lawrence Erlbaum.

Correa, T., Hinsley, A. W., \& De Zuniga, H. G. (2010). Who interacts on the Web? The intersection of users' personality and social media use. Computers in Human Behavior, 26(2), 247-253.

Davis, F. D. (1985). A technology acceptance model for empirically testing new end-user information systems: theory and results (doctoral dissertation). Sloan School of Management, Massachusetts Institute of Technology, MA.

Davis, F. D. (1989). Perceived usefulness, perceived ease of use, and user acceptance of information technology. MIS Quarterly, 13(3), 319-340.

Delisle, M. (2017), App usage through the ages-targeting older, more lucrative users. Digital Turbine. Retrieved from https://www.digitalturbine.com/blog/mobile-marketing/app-usage-through-the-agestargeting-older-more-lucrative-users/

Deng, L., Turner, D. E., Gehling, R., \& Prince, B. (2010). User experience, satisfaction, and continual usage intention of IT. European Journal of Information Systems, 19(1), 60-75.

Dishaw, M. T., \& Strong, D. M. (1999). Extending the technology acceptance model with task-technology fit constructs. Information \& Management, 36(1), 9-21. 
Fang, Y., Qureshi, I., Sun, H., McCole, P., Ramsey, E., \& Lim, K. H. (2014). Trust, satisfaction, and online repurchase intention. MIS Quarterly, 38(2), 407-427.

Ghose, A., \& Han, S. P. (2014). Estimating demand for mobile applications in the new economy. Management Science, 60(6), 1470-1488.

Hair, J. F., Hult, G. T. M., Ringle, C., \& Sarstedt, M. (2016). A primer on partial least squares structural equation modeling (PLS-SEM). Thousand Oaks, CA: Sage.

Hair, J. F., Ringle, C. M., \& Sarstedt, M. (2011). PLS-SEM: Indeed a silver bullet. The Journal of Marketing Theory and Practice, 19(2), 139-152.

Hamilton, R. W., Rust, R. T., \& Dev, C. S. (2017). Which features increase customer retention? MIT Sloan Management Review, 58(2), 79-84.

Harman, H. H. (1976). Modern factor analysis. Chicago, IL: University of Chicago Press.

Henseler, J., Dijkstra, T. K., Sarstedt, M., Ringle, C. M., Diamantopoulos, A., Straub, D. W., Ketchen, D. J., Jr., Hair, J. F., Hult, T. M., \& Calantone, R. J. (2014). Common beliefs and reality about PLS: Comments on Rönkkö and Evermann (2013). Organizational Research Methods, 17(2), 182-209.

Henseler, J., Ringle, C. M., \& Sarstedt, M. (2015). A new criterion for assessing discriminant validity in variance-based structural equation modeling. Journal of the Academy of Marketing Science, 43(1), 115-135.

Ho, C. K., Ke, W., Liu, H., \& Chau, P. Y. (2020). Separate versus joint evaluation: The roles of evaluation mode and construal level in technology adoption. MIS Quarterly, 44(2), 725-746.

Hsiao, C.-H., Chang, J.-J., \& Tang, K.-Y. (2016). Exploring the influential factors in continuance usage of mobile social apps: Satisfaction, habit, and customer value perspectives. Telematics and Informatics, 33(2), 342-355.

lqbal. (2019). App download and usage statistics (2019). Retrieved from https://www.businessofapps.com/data/app-statistics/

Islam, A. N., Mäntymäki, M., \& Bhattacherjee, A. (2017). Towards a decomposed expectation confirmation model of IT continuance: The role of usability. Communications of the Association for Information Systems, 40, 502-523

Lee, D. Y., \& Lehto, M. R. (2013). User acceptance of YouTube for procedural learning: An extension of the technology acceptance model. Computers \& Education, 61, 193-208.

Lai, V. S., \& Li, H. (2005). Technology acceptance model for internet banking: An invariance analysis. Information \& Management, 42(2), 373-386.

Liang, T.-P., Li, X., Yang, C.-T., \& Wang, M. (2015). What in consumer reviews affects the sales of mobile apps: A multifacet sentiment analysis approach. International Journal of Electronic Commerce, 20(2), 236-260.

Lim, S. L., Bentley, P. J., Kanakam, N., Ishikawa, F., \& Honiden, S. (2014). Investigating country differences in mobile app user behavior and challenges for software engineering. IEEE Transactions on Software Engineering, 41(1), 40-64.

Lindell, M. K., \& Whitney, D. J. (2001). Accounting for common method variance in cross-sectional research designs. Journal of Applied Psychology, 86(1), 114-121.

Liu, C. Z., Au, Y. A., \& Choi, H. S. (2014). Effects of freemium strategy in the mobile app market: An empirical study of Google play. Journal of Management Information Systems, 31(3), 326-354.

Liu, Y., Armstrong, D. J., \& Riemenschneider, C. (2018). The relationship between information systems (IS) assets, organizational capabilities, and IS-enabled absorptive capacity in US state information technology departments. Communications of the Association for Information Systems, 42, 125-146.

Liu, Y., \& Tang, X. (2018). The effects of online trust-building mechanisms on trust and repurchase intentions: An empirical study on eBay. Information Technology \& People, 31(3), 666-687. 
MacKenzie, S. B., Podsakoff, P. M., \& Podsakoff, N. P. (2011). Construct measurement and validation procedures in MIS and behavioral research: Integrating new and existing techniques. MIS Quarterly, 35(2), 293-334.

Manis, K. T., \& Choi, D. (2019). The virtual reality hardware acceptance model (VR-HAM): Extending and individuating the technology acceptance model (TAM) for virtual reality hardware. Journal of Business Research, 100, 503-513.

Marinković, V., Đorđević, A., \& Kalinić, Z. (2020). The moderating effects of gender on customer satisfaction and continuance intention in mobile commerce: A UTAUT-based perspective. Technology Analysis \& Strategic Management, 32(3), 306-318.

Mcknight, D. H., Cummings, L. L. \& Chervany, N. L. (1998), Initial trust formation in new organizational relationships. Academy of Management Review, 23(3), 473-490.

Moore, G. C., \& Benbasat, I. (1991). Development of an instrument to measure the perceptions of adopting an information technology innovation. Information Systems Research, 2(3), 192-222.

Moore, J. F. (1993). Predators and prey: A new ecology of competition. Harvard Business Review, 71(3), 75-83.

Morgan, J. (2017). The rise of the mobile economy and what it means for our future. Medium. Retrieved from https://medium.com/jacob-morgan/the-rise-of-the-mobile-economy-and-what-it-means-for-ourfuture-5f5ba82c988f

Nelson, R. R., \& Winter, S. G. (1982). An evolutionary theory of economic change. Cambridge, MA: Harvard University Press.

Pavlou, P. A., \& Gefen, D. (2004). Building effective online marketplaces with institution-based trust. Information Systems Research, 15(1), 37-59.

Petter, S., Straub, D., \& Rai, A. (2007). Specifying formative constructs in information systems research. MIS Quarterly, 31(4), 623-656.

Podsakoff, P. M., MacKenzie, S. B., Lee, J.-Y., \& Podsakoff, N. P. (2003). Common method biases in behavioral research: A critical review of the literature and recommended remedies. Journal of Applied Psychology, 88(5), 879-903.

Rayle, L., Shaheen, S., Chan, N., Dai, D., \& Cervero, R. (2014). App-based, on-demand ride services: Comparing taxi and ridesourcing trips and user characteristics in San Francisco. Retrieved from http://innovativemobility.org/wpcontent/uploads/2015/01/RidesourcingWhitePaper_Nov2014Update.pdf

Ringle, C. M., Wende, S., \& Becker, J.-M. (2015). SmartPLS 3. Bönningstedt: SmartPLS. Retrieved from http://www.smartpls.com

Robson, A. J. (2005). Complex evolutionary systems and the red queen. The Economic Journal, 115(504), F211-F224.

Rodde, T. (2018). $21 \%$ of users abandon an app after one use. Upland. Retrieved from http://info.localytics.com/blog/21-percent-of-users-abandon-apps-after-one-use

Saffarizadeh, K., Jabr, W., \& Keil, M. (2018). Update assimilation in app markets: Is there such a thing as too many updates? In Proceedings of the 39th International Conference on Information Systems.

Sivakumaran, M., \& lacopino, P. (2018). The mobile economy 2018. GSMA. Retrieved from https://www.gsma.com/mobileeconomy/

Sobel, M. E. (1982). Asymptotic confidence intervals for indirect effects in structural equation models. Sociological Methodology, 13, 290-312.

Statista. (2019). Worldwide mobile app revenues in 2014 to 2023 (in billion U.S. dollars). Retrieved from https://www.statista.com/statistics/269025/worldwide-mobile-app-revenue-forecast/

Statista. (2020). Number of mobile app downloads worldwide from 2016 to 2019 (in billions). Retrieved from downloads/ https://www.statista.com/statistics/271644/worldwide-free-and-paid-mobile-app-store- 
Steelman, Z. R., Hammer, B. I., \& Limayem, M. (2014). Data collection in the digital age: Innovative alternatives to student samples. MIS Quarterly, 38(2), 355-A320.

Sterling, G. (2016). All digital growth now coming from mobile usage-comScore. MarTech. Retrieved from http://marketingland.com/digital-growth-now-coming-mobile-usage-comscore-171505

Tellis, G. J., \& Crawford, C. M. (1981). An evolutionary approach to product growth theory. The Journal of Marketing, 45(4), 125-132.

Tiwana, A. (2015). Evolutionary competition in platform ecosystems. Information Systems Research, 26(2), 266-281.

Tiwana, A., Konsynski, B., \& Bush, A. A. (2010). Research commentary-platform evolution: Coevolution of platform architecture, governance, and environmental dynamics. Information Systems Research, 21(4), 675-687.

Turel, O., Serenko, A., \& Giles, P. (2011). Integrating technology addiction and use: An empirical investigation of online auction users. MIS Quarterly, 1043-1061.

Venkatesh, V., \& Davis, F. D. (1996). A model of the antecedents of perceived ease of use: Development and test. Decision Sciences, 27(3), 451-481.

Venkatesh, V., \& Davis, F. D. (2000). A theoretical extension of the technology acceptance model: Four longitudinal field studies. Management Science, 46(2), 186-204.

Venkatesh, V., \& Goyal, S. (2010). Expectation disconfirmation and technology adoption: polynomial modeling and response surface analysis. MIS Quarterly, 34(2), 281-303.

Venkatesh, V., Morris, M. G., Davis, G. B., \& Davis, F. D. (2003). User acceptance of information technology: Toward a unified view. MIS Quarterly, 27(3), 425-478.

Venkatesh, V., Thong, J. Y., Chan, F. K., Hu, P. J. H., \& Brown, S. A. (2011). Extending the two-stage information systems continuance model: Incorporating UTAUT predictors and the role of context. Information Systems Journal, 21(6), 527-555.

Venkatesh, V., Thong, J. Y., \& Xu, X. (2016). Unified theory of acceptance and use of technology: A synthesis and the road ahead. Journal of the Association for Information Systems, 17(5), 328-376.

Wang, M., \& Li, X. (2017). Effects of the aesthetic design of icons on app downloads: Evidence from an android market. Electronic Commerce Research, 17(1), 83-102.

Wang, Q., Li, B., \& Singh, P. V. (2018). Copycats vs. original mobile apps: A machine learning copycatdetection method and empirical analysis. Information Systems Research, 29(2), 273-291.

Webiotic. (2019). How often should you update your app? The complete guide on updating apps. Retrieved from https://www.webiotic.com/how-often-should-you-update-your-app/

Wong, W. E., Li, X., Laplante, P. A., \& Siok, M. (2017). Be more familiar with our enemies and pave the way forward: A review of the roles bugs played in software failures. Journal of Systems and Software, 133(11), 68-94. 


\section{Appendix: Main Constructs, Items, and Sources}

\begin{tabular}{|c|c|c|}
\hline Construct & Items & Sources \\
\hline \multirow{5}{*}{$\begin{array}{c}\text { Effectiveness of } \\
\text { strategic evolution (M = } \\
5.609 ; \mathrm{SD}=1.042 ; \\
\mathrm{AVE}=0.730 ; \\
\text { Cronbach's } \alpha=0.907 ; \\
\mathrm{CR}=0.931)\end{array}$} & $\begin{array}{l}\text { I believe that the newly added features (e.g., functionalities, } \\
\text { user interfaces, modules, components etc.) are useful }\end{array}$ & \multirow{5}{*}{$\begin{array}{l}\text { Newly developed based } \\
\text { on construct definition and } \\
\text { relevant literature (e.g., } \\
\text { Pavlou \& Gefen, 2004; } \\
\text { Fang et al., 2014) }\end{array}$} \\
\hline & $\begin{array}{l}\text { I believe that the newly added features (e.g., functionalities, } \\
\text { user interfaces, modules, components etc.) are helpful }\end{array}$ & \\
\hline & $\begin{array}{l}\text { I believe that the newly added features (e.g., functionalities, } \\
\text { user interfaces, modules, components etc.) are reliable }\end{array}$ & \\
\hline & $\begin{array}{l}\text { I believe that the newly added features (e.g., functionalities, } \\
\text { user interfaces, modules, components etc.) are enjoyable }\end{array}$ & \\
\hline & $\begin{array}{l}\text { I believe that adding New features (e.g., functionalities, user } \\
\text { interfaces, modules, components etc.) are practical }\end{array}$ & \\
\hline \multirow{4}{*}{$\begin{array}{c}\text { Effectiveness of } \\
\text { operational evolution } \\
(\mathrm{M}=5.656 ; \mathrm{SD}= \\
1.071 ; \mathrm{AVE}=0.779 ; \\
\text { Cronbach's } \alpha=0.905 ; \\
\mathrm{CR}=0.934)\end{array}$} & $\begin{array}{l}\text { I feel that it effectively reduces the errors of the app by } \\
\text { refining existing features (e.g., functionalities, user } \\
\text { interfaces, modules, components etc.) }\end{array}$ & \multirow{4}{*}{$\begin{array}{l}\text { Newly developed based } \\
\text { on construct definition and } \\
\text { relevant literature (e.g., } \\
\text { Pavlou \& Gefen, 2004; } \\
\text { Fang et al., 2014) }\end{array}$} \\
\hline & $\begin{array}{l}\text { I feel that it usefully solves the crashes of the app by refining } \\
\text { existing features (e.g., functionalities, user interfaces, } \\
\text { modules, components etc.) }\end{array}$ & \\
\hline & $\begin{array}{l}\text { I feel that it significantly improves the quality of the app by } \\
\text { refining existing features (e.g., functionalities, user } \\
\text { interfaces, modules, components etc.) }\end{array}$ & \\
\hline & $\begin{array}{l}\text { I feel that it obviously enhances the stability of the app by } \\
\text { refining existing features (e.g., functionalities, user } \\
\text { interfaces, modules, components etc.) }\end{array}$ & \\
\hline \multirow{4}{*}{$\begin{array}{c}\text { Effectiveness of } \\
\text { evolution speed }(\mathrm{M}= \\
5.530 ; \mathrm{SD}=1.093 ; \\
\text { AVE }=0.810 ; \\
\text { Cronbach's } \alpha=0.922 ; \\
\text { CR }=0.945)\end{array}$} & $\begin{array}{l}\text { I believe the speed of app upgrade is appropriate to address } \\
\text { the customers' requirements and the environmental changes. }\end{array}$ & \multirow{4}{*}{$\begin{array}{l}\text { Adapted based on } \\
\text { construct definition and } \\
\text { relevant literature (e.g., } \\
\text { Pavlou \& Gefen, 2004; } \\
\text { Fang et al., 2014; Tiwana, } \\
\text { 2015) }\end{array}$} \\
\hline & $\begin{array}{l}\text { I believe the speed of app upgrade is effective to address the } \\
\text { customers' requirements and the environmental changes. }\end{array}$ & \\
\hline & $\begin{array}{l}\text { I believe the speed of app upgrade is fast to address the } \\
\text { customers' requirements and the environment changes. }\end{array}$ & \\
\hline & $\begin{array}{l}\text { The speed of app upgrade is successful to address the } \\
\text { customers' requirements and the environmental changes. }\end{array}$ & \\
\hline \multirow{9}{*}{$\begin{array}{c}\text { Perceived app } \\
\text { usefulness } \\
(\mathrm{M}=5.828 ; \mathrm{SD}= \\
0.925 ; \mathrm{AVE}=0.592 ; \\
\text { Cronbach's } \alpha=0.914 ; \\
\mathrm{CR}=0.928)\end{array}$} & I evaluate the app as useless — useful & \multirow{9}{*}{$\begin{array}{l}\text { Deng et al. (2010), } \\
\text { Venkatesh \& Goyal (2010) }\end{array}$} \\
\hline & I evaluate the app as impractical $\longrightarrow$ practical & \\
\hline & I evaluate the app as unnecessary — necessary & \\
\hline & I evaluate the app as unfunctional —_ functional & \\
\hline & I evaluate the app as unhelpful — helpful & \\
\hline & I evaluate the app as inefficient $\longrightarrow$ efficient & \\
\hline & I evaluate the app as ineffective $\longrightarrow$ effective & \\
\hline & I evaluate the app as harmful — beneficial & \\
\hline & I evaluate the app as unproductive $\longrightarrow$ productive & \\
\hline \multirow{6}{*}{$\begin{array}{c}\text { Perceived app ease of } \\
\text { use }(\mathrm{M}=6.317 ; \mathrm{SD}= \\
0.689 ; \mathrm{AVE}=0.705 ; \\
\text { Cronbach's } \alpha=0.916 ; \\
\mathrm{CR}=0.935)\end{array}$} & It is easy for me to become skillful at using the app & \multirow{6}{*}{$\begin{array}{l}\text { Abdullah et al. } \\
\qquad(2016)\end{array}$} \\
\hline & I find it is easy to get the app to do what I want it to do & \\
\hline & My interaction with the app is clear & \\
\hline & My interaction with the app is understandable & \\
\hline & I found that the app is easy to use & \\
\hline & Learning to operate the app is easy for me & \\
\hline \multirow{6}{*}{$\begin{array}{c}\text { App continuance } \\
\text { intention } \\
(\mathrm{M}=4.684 ; \mathrm{SD}= \\
0.768 ; \mathrm{AVE}=0.711 ; \\
\text { Cronbach's } \alpha=0.492 ; \\
\mathrm{CR}=0.925)\end{array}$} & I intend to continue using the app & \multirow{6}{*}{ Venkatesh \& Goyal (2010) } \\
\hline & I predict I would continue using the app & \\
\hline & I plan to continue using the app & \\
\hline & I intend to continue using the app in the future & \\
\hline & I will always try to use the app in my daily life & \\
\hline & I will keep using the app as regularly as I do now ${ }^{*}$ & \\
\hline
\end{tabular}




\begin{tabular}{|c|c|c|}
\hline Construct & Items & Sources \\
\hline & If I could, I would like to discontinue my use of the app* & \\
\hline \multirow{4}{*}{$\begin{array}{c}\text { App complexity }(M= \\
2.750 ; \mathrm{SD}=1.138 ; \\
\text { AVE }=0.855 \\
\text { Cronbach's } \alpha=0.915 ; \\
\text { CR }=0.946)\end{array}$} & $\begin{array}{l}\text { Compared to other apps with which I am familiar, this app has } \\
\text { relatively complex design }\end{array}$ & \multirow{4}{*}{ Tiwana (2015) } \\
\hline & $\begin{array}{l}\text { Compared to other apps with which I am familiar, this app is } \\
\text { technically complex to develop }\end{array}$ & \\
\hline & $\begin{array}{l}\text { Compared to other apps with which I am familiar, this app } \\
\text { uses complex development processes }\end{array}$ & \\
\hline & $\begin{array}{l}\text { Compared to other apps with which I am familiar, this app } \\
\text { uses few development tools to build* }\end{array}$ & \\
\hline \multirow{3}{*}{$\begin{array}{l}\text { Disposition toward trust } \\
\quad(\mathrm{M}=3.795 ; \mathrm{SD}= \\
1.101 ; \mathrm{AVE}=0.795 ; \\
\text { Cronbach's } \alpha=0.909 ; \\
\mathrm{CR}=0.920)\end{array}$} & I generally trust other people & \multirow{3}{*}{ Mcknight et al. (1998) } \\
\hline & I generally have faith in humanity & \\
\hline & $\begin{array}{l}\text { I generally trust other people unless they give me a reason } \\
\text { not to }\end{array}$ & \\
\hline
\end{tabular}




\section{About the Authors}

Yi Liu is an Assistant Professor of Management Information Systems at the H-E-B School of Business \& Administration, University of the Incarnate Word. He obtained his PhD from Florida State University. Yi Liu has four research areas: platform-centric competition, IT business value and strategy, e-commerce, and business analytics. His studies have been published in the Journal of Information Technology \& People, Communication of Associate Information Systems, Information Systems Frontiers, and European Conference on Information Systems (ECIS). He has served on the review board of Journal of Global Business Insights (JGBI).

Jiahe Song is an Assistant Professor of Business Information Systems in the Haworth College of Business at Western Michigan University. She received her PhD in Business Information Systems from Auburn University. Her current research interests include social media, big data, health IT at individual, organizational, and industry levels. Her research has appeared in Journal of Medical Internet Research, Information Technology \& People, International Journal of Medical Informatics, International Journal of Physical Distribution \& Logistic Management, International Journal of Information Management, and Information Systems Management.

Xuan Wang is an Assistant Professor of Information Systems at Robert C. Vackar College of Business \& Entrepreneurship, The University of Texas Rio Grande Valley. She received her PhD in Information Systems and Decision Science from E. J. Ourso College of Business, Louisiana State University. Her interests include causal inference, big data analytics and virtual communities. Her research has been published in Information Systems Management, Journal of Organizational and End-User Computing, and Information Systems Frontiers. She also has been presented in the conferences such as Decision Science Institute (DSI), Americas Conference on Information Systems (AMCIS), and Hawaii International Conference on System Sciences (HICSS).

Xinlin Tang is an Associate Professor of Management Information Systems at the College of Business, Florida State University. She holds a PhD from Georgia State University. Her current research focuses on digital innovation and business value, IT-enable knowledge management, and emerging technologies. Her research has been published or forthcoming in a number of high-impact journals, including Information Systems Research, Journal of Management Information Systems, Journal of Operations Management, and IEEE Transactions on Engineering Management. She has served as associate editor for MIS Quarterly and on the review board of IEEE Transactions on Engineering Management.

Copyright ( 2021 by the Association for Information Systems. Permission to make digital or hard copies of all or part of this work for personal or classroom use is granted without fee provided that copies are not made or distributed for profit or commercial advantage and that copies bear this notice and full citation on the first page. Copyright for components of this work owned by others than the Association for Information Systems must be honored. Abstracting with credit is permitted. To copy otherwise, to republish, to post on servers, or to redistribute to lists requires prior specific permission and/or fee. Request permission to publish from: AIS Administrative Office, P.O. Box 2712 Atlanta, GA, 30301-2712 Attn: Reprints via e-mail from publications@aisnet.org. 